\title{
Psicologia, Ciência e Construcionismos: Dando Sentido ao Self
}

\author{
Emerson F. Rasera ${ }^{12}$ \\ Carla Guanaes \\ Marisa Japur ${ }^{3}$ \\ Universidade de São Paulo, Ribeirão Preto
}

\begin{abstract}
Resumo
O construcionismo social tem sido proposto como um conjunto de elaborações da crise paradigmática que tem sofrido as ciências nas últimas décadas. A complexidade e riqueza de tais elaborações dificultam uma descrição única e consensualmente aceita sobre o construcionismo social. Neste artigo temos como objetivo explorar as propostas de Kenneth J. Gergen e Rom Harré acerca do construcionismo social, seus pressupostos, a visão de ciência promovida por cada uma delas, buscando compreender as implicações para a construção de suas descrições de self. Se é possível identificarmos diversas semelhanças nas propostas destes autores, algumas diferenças significativas marcam a distinção de suas posturas, e servem para mapear o campo de tensões no qual outros autores construcionistas buscam ativamente se posicionar.

Palavras-chave: Construcionismo Social; teoria; self.
\end{abstract}

Psychology, Science and Constructionisms: Making Sense of Self

\begin{abstract}
Social constructionism has been proposed as a set of answers for the scientific paradigmatic crisis of last decades. The complexity and richness of its statements make difficult a unitary and consensual description of what is social constructionism among its proponents. Our objective in this article is to explore in more details Kenneth J. Gergen and Rom Harré's view of social constructionism, its assumptions and view of science, thus favoring an understanding about the way these authors describe and understand the self. Although it is possible to identify many similarities in their proposals, some differences clearly separate their positions, and help to map this field of tensions in which other constructionist authors try to position themselves.

Keywords: Social Constructionism; theory; self.
\end{abstract}

O construcionismo social ${ }^{4}$ tem sido proposto como um conjunto de elaborações da crise paradigmática que têm sofrido as ciências nas últimas décadas (Gergen, 1985). Ele tem se desenvolvido no campo da Psicologia baseado em uma concepção alternativa do funcionamento da ciência e suas formas de investigação. Podemos entender o construcionismo como decorrente de uma tensão historicamente muito antiga, entre empiristas e racionalistas, que tem ganhado uma forma e um nome específicos nas últimas décadas, promovidos por um conjunto de autores (Gergen, 1997; Harré, 1998; Parker, 1998; Shotter, 1993; Spink, 1999) que de diferentes modos têm revisto tal tensão.

A diversidade e complexidade destes modos de compreensão dificultam uma definição única, amplamente aceita, do que vem a ser o construcionismo social. Alguns definem o construcionismo como uma "consciência compartilhada" (Gergen, 1997), outros afirmam que os autores construcionistas

\footnotetext{
${ }^{1}$ Apoio: FAPESP

${ }^{2}$ Agradecimentos a Ana Paula S. da Silva, Jan Valsiner e Maria Clotilde RossetiFerreira pelos comentários e sugestões na redação deste artigo.

${ }^{3}$ Endereço para correspondência: Marisa Japur, Faculdade de Filosofia, Ciências e Letras de Ribeirão Preto da Universidade de São Paulo, Av. dos Bandeirantes, 3900, 14040 901, Ribeirão Preto, São Paulo.E-mail:mjapur@ffclrp.usp.br

${ }^{4}$ Os termos construcionismo social e construcionismo são utilizados como sinônimos neste artigo.
}

têm entre si apenas uma "semelhança familiar" (Burr, 1995) e outros ainda afirmam não existir uma psicologia construcionista (Potter, citado em Nightingale \& Cromby, 1999). Se por um lado, é possível rapidamente fazer algumas comparações nas quais marcamos a distinção entre autores construcionistas e não-construcionistas, por outro, uma certa imprecisão sobre o que os une permanece.

\section{Construcionismo ou Construcionismos: Entendendo um Campo de Tensões}

Algumas tentativas de definição e classificação das propostas construcionistas foram realizadas. Danzinger (1997) descreve um light constructionism e um dark constructionism, Zuriff (1998) distingue um construcionismo empírico de um construcionismo metafísico, Shotter (1993) fala de um construcionismo responsivo-retórico, Gergen $(1985,1999)$ e Harré (1998) propõem diferentes pressupostos para o construcionismo.

Segundo Rasera (2002), através de uma análise dos diálogos entre certas posturas construcionistas, é possível identificar um jogo de abertura e restrição, de oscilações entre a afirmação da diferença e a consideração pela semelhança, ou seja, ora marcando o que distingue o construcionismo de outras perspectivas, ora apontando o caráter contextual desta distinção. Este jogo promovido por 
determinados autores (Gergen, 1997; Hacking, 1999) faz da definição/distinção do construcionismo um pseudoproblema. Contudo, se uma descrição única do construcionismo não precisa ser buscada, uma análise comparativa sobre as especificidades de algumas propostas pode dar visibilidade a algumas tensões que compõem o campo de preocupações construcionistas, clareando as opções de cada autor e as implicações destas nas análises dos objetos estudados.

Assim, neste artigo, temos como objetivo explorar as propostas de Kenneth J. Gergen e Rom Harré acerca do construcionismo social, seus pressupostos, a visão de ciência promovida por cada uma delas, buscando compreender as implicações para a construção de suas descrições do self. Trata-se de um exercício reflexivo que busca situar tais propostas a partir de seu próprio vocabulário e preocupações específicas, preservando a riqueza de cada descrição e explicitando a heterogeneidade do construcionismo social.

A escolha destes autores se pautou pela auto-identificação dos mesmos como construcionistas, por apresentarem uma definição sistematizada desta perspectiva, associada ao fato de ambos terem produzido trabalhos específicos a respeito do conceito de self (Gergen, 1991; Harré, 1998), facilitando a tarefa analítica aqui pretendida. A escolha do conceito de self como foco de nosso estudo deveu-se à centralidade deste conceito para a Psicologia, sendo assim um ótimo exemplo para explicitarmos as contribuições construcionistas para a mesma.

\section{A Ciência como Empreendimento da Cultura: Pós- modernidade, Self e Discurso}

Apesar das divergências entre os pesquisadores na descrição do construcionismo, é possível identificar claramente a proposta de uma Psicologia de cunho construcionista nos trabalhos de Gergen, a qual está articulada a uma forma de pensar a prática científica e o desenvolvimento do conhecimento.

Gergen (1999), na tentativa de descrever algumas idéias centrais sobre o construcionismo social, enfatiza:

1) a especificidade cultural e histórica das formas de conhecermos o mundo. As descrições do mundo não guardam correspondência com uma realidade situada para além das formas de dizê-la, mas são elas próprias maneiras de construção desta realidade, organizadas a partir de determinadas condições sócio-históricas concretas dos sistemas de significação;

2) a primazia dos relacionamentos humanos na produção e sustentação do conhecimento. As descrições sobre o mundo são resultado da coordenação da ação humana, da construção de uma comunidade lingüística que a partir de processos sociais de negociação produzem significados locais duráveis no tempo;

3) a interligação entre conhecimento e ação. Diferentes formas de descrever o mundo, de produzir explicações, de gerar conhecimento, implicam em diferentes possibilidades de dar sentido ao mundo e de agir socialmente;

4) a valorização de uma postura crítica e reflexiva. Dado que o conhecimento está associado a determinadas condições sociais de produção, o construcionismo convida a uma postura crítica e reflexiva sobre os saberes gerados que promova a transformação de nossas próprias tradições.

A partir destas idéias, a ciência numa perspectiva construcionista, conforme a descrição de Gergen, é um empreendimento da cultura, e deixa de ser pautado por uma epistemologia dualista da distinção sujeito-objeto, sendo orientado por uma epistemologia social. A busca pela verdade realizada pela mente individual é substituída por questões de inteligibilidade, utilidade social e valor humano existentes em determinados padrões de relacionamento social. A ênfase na natureza contingente da realidade e no caráter social de produção do conhecimento científico desafia a proposição tanto de um objeto, como de uma metodologia únicos na Psicologia.

Gergen (1997) propõe uma visão de ciência como instrumento pragmático de sustentação ou questionamento das inteligibilidades tradicionais. A redescrição construcionista da ciência psicológica como prática social contextualizada incentiva transformações teóricas e metodológicas no próprio fazer científico visando contribuições que potencializem seu papel na cultura.

A contribuição da ciência para a manutenção das tradições existentes, numa perspectiva construcionista, se dá através da formulação de inteligibilidades teóricas que permitam determinados entendimentos que facilitem a coordenação das ações humanas dentro de limites sócio-culturais prévios. Por outro lado, a ciência pode promover uma desestabilização das convenções sociais a partir de investigações que propiciem uma crítica interna, uma crítica cultural, até uma pesquisa de desalojamento (scholarship of dislogment). A crítica interna se refere à avaliação e reflexão por parte dos cientistas de suas descrições do real e as práticas associadas. Expandindo-se esta postura avaliativa, temos uma crítica cultural, na qual o debate está relacionado a perspectivas morais e políticas ampliadas. Dado que estas críticas se pautam, muitas vezes, em valores específicos, tais como igualdade e justiça, o construcionismo social também convida a uma pesquisa de desalojamento, isto é, a uma forma de investigação focada na ruptura geral do convencional e menos investida de uma posição particular de valor.

Além destas formas de investigação crítica e desestabilizadora, a contribuição do construcionismo social, segundo Gergen (1997), expande-se para a transformação e inovação cultural. Neste sentido, três formas de prática de pesquisa promovidas pelo construcionismo são: a desconstrução, através da qual o caráter construído das coisas é explicitado, suspeitando da autoridade e transcendência de qualquer descrição; a 
democratização, através da qual múltiplos parceiros são convidados a dialogar sobre as formas e os resultados da produção científica; e a reconstrução, na qual esforços são dirigidos para a proposição de novas visões, vocabulários e práticas que promovam a transformação cultural.

Estas posturas desconstrutiva e de crítica interna promovidas pelo construcionismo social produzem na Psicologia a necessidade de se rever as descrições/definições do conceito de self, considerado por muito tempo o objeto de estudo privilegiado desta ciência, e de se propor novas formulações. Assim, o estudo do self está presente em diversos trabalhos de Gergen (1991, 1997, 1999). Associado às críticas ao realismo e ao essencialismo de muitas definições do self e suas contribuições para uma cultura individualista, Gergen ao investigar o self abandona a busca pela definição universal de um self nuclear, organizado, estável e autêntico como no projeto da ciência moderna.

De sua ênfase no estudo da linguagem decorre a descrição do self como um discurso: de um lado, buscando situar as condições sócio-históricas concretas de emergência de um novo vocabulário sobre o self, e de outro, analisando as formas pelas quais as narrativas sobre o self socialmente disponíveis são utilizadas na sustentação dos relacionamentos. Há assim uma exteriorização, multiplicação e contextualização histórica da construção do self.

Em seu livro The saturated self, Gergen (1991) analisa as condições de emergência de um nova forma de descrever o self - o self saturado, identificadas ao processo de saturação social promovido pelo desenvolvimento tecnológico, especialmente dos meios de transporte, das telecomunicações e variadas formas de mídia, nas últimas décadas. O self saturado aí descrito relaciona-se aos padrões de relacionamento social de um mundo pós-moderno, no qual há um intenso fluxo e contato de pessoas e tradições que levam ao questionamento reflexivo, a inúmeras possibilidades de negociação e reconstrução. Neste processo de saturação social, emerge um self povoado por múltiplas e contraditórias possibilidades de ser, para o qual se ampliam as oportunidades de relacionamento com os outros, se complexificam os diálogos internos e aumenta a dificuldade de compromisso com uma identidade assimilável à idéia de unicidade. Segundo Gergen (1991, p. 16):

Crítico para o meu argumento é a proposta de que a saturação social traz com ela uma perda generalizada de nossas hipóteses do self verdadeiro e passível de conhecimento. À medida que absorvemos múltiplas vozes, consideramos que cada 'verdade' é relativizada por nossa consciência simultânea de alternativas atraentes. Nos tornamos conscientes que cada verdade sobre nós mesmos é uma construção do momento, verdadeira apenas por um período de tempo e no interior de certos relacionamentos.
A ampliação da conexão social exige do indivíduo uma multiplicidade de investimentos de self que leva a um processo de multifrenia caracterizado por: a) uma "vertigem do dever", devido às necessidades de manutenção dos inúmeros relacionamentos; b) uma "expansão da autodúvida", dada a diversidade de formas possíveis de se relacionar e descrever o mundo; e c) uma "recessão da racionalidade", pelo reconhecimento da validade local de determinadas formas de ser e agir.

Este processo de saturação social está associado à descrição de um self relacional. Considerando a presença desgastada dos discursos românticos e modernos do self, Gergen chama a atenção para a emergência na cultura pósmoderna de sinais de uma concepção relacional de self, na qual aspectos prévios e referidos ao selfindividual se tornam nessa descrição parte de relacionamentos.

Entre estes sinais podemos apontar, primeiro, as tentativas de explicitar o domínio social da história pessoal realizadas por autores que mostram como as convenções socialmente estabelecidas sobre a narrativa histórica determinam como compreendemos o passado. Neste sentido, a autobiografia está associada a uma sociobiografia, a uma negociação da memória compartilhada. Segundo, a proposição da emoção como performance cultural. Há, aqui, um deslocamento da biologia para a cultura no entendimento da emoção. Tal como numa encenação, o sistema biológico é requerido para expressar determinada emoção, mas ele não requer as ações em si mesmo. Há cenários emocionais aprendidos culturalmente que disponibilizam e demandam determinadas suplementações entre os participantes num jogo partilhado de expressão emocional. Terceiro, a descrição da moralidade como fenômeno relacional, existindo para além do indivíduo. As justificativas para uma boa ação moral encontram-se disponíveis na cultura e são utilizadas pelas pessoas. As ações das pessoas não são inerentemente morais ou imorais. A pluralidade de realidades sociais nas quais as pessoas vivem pode causar tensões e ambigüidades na definição do que é moralmente aceitável, sendo a imoralidade possível pela divergência de perspectivas entre grupos sociais. A decisão moral é assim circunscrita culturalmente.

Nesta perspectiva construcionista, há um convite à multiplicidade de discursos sobre o self, ou nos termos de Bakhtin, a uma heteroglossia do ser, a "um viver na multiplicidade de vozes dentro da esfera humana" (Bakhtin, citado em Gergen, 1991, p. 247). Promove-se então um enriquecimento do discurso do self, o qual pode ser buscado na investigação de descrições históricas e culturais do self, através das quais se possa integrar outras inteligibilidade às já disponíveis na cultura.

Em outro trabalho, Self-narration in social life (Gergen, 1997), o foco deixa de se situar no nível das relações dos discursos na sociedade, direcionando-se para uma pragmática da 
narrativa de self. Ele, então, analisa as narrativas de self como forma de descrição social, como recurso conversacional, como um "implemento lingüístico embutido em seqüências convencionais de ação e empregados nos relacionamentos de tal forma a sustentar, incentivar ou impedir determinadas ações" (p. 187).

Considerando esta concepção, a inteligibilidade do self está relacionada à estrutura das descrições narrativas. Para este autor, as propriedades das boas narrativas são histórica e culturalmente determinadas, sendo que as convenções narrativas contemporâneas se organizam a partir dos seguintes critérios: 1) estabelecimento de um desfecho; 2) seleção de eventos relevantes para o desfecho; 3) ordenação dos eventos; 4) preservação da estabilidade da identidade da personagem; 5) presença de ligações causais entre os eventos; e 6) indicação de signos de demarcação. Narrativas de self pautadas por estes critérios promovem, em nosso contexto sóciohistórico atual, um maior senso de realidade e eficácia social, favorecendo um maior senso de coerência e direção na vida.

Segundo Gergen (1997), certas formas básicas de narrativa são amplamente compartilhadas na cultura. Para ele, todos os enredos podem ser convertidos para uma forma linear em termos de mudanças avaliativas ao longo do tempo, segundo três formas narrativas rudimentares: estabilidade, progressiva e regressiva. Nelas, o movimento na dimensão avaliativa ao longo do tempo permanece imutável, é crescente ou decrescente respectivamente. Estas formas narrativas rudimentares geram variações mais complexas, tais como a narrativa trágica, na qual há uma narrativa progressiva seguida de uma narrativa regressiva e a saga heróica, na qual há uma série de fases de narrativas progressivas e regressivas.

As narrativas podem se referir a períodos amplos de tempo, as macronarrativas, bem como eventos de curta duração, as micronarrativas. Estes dois tipos de narrativas podem se entrelaçar gerando narrativas encaixadas. Nestas, juntamente com relatos de um tempo distante há descrições de eventos recentes. Segundo Gergen (1997), na medida que a cultura valoriza a consistência entre as narrativas, as macronarrativas passam a ter uma importância significativa, sendo a base sobre a qual se constrói outras narrativas. Assim, narrativas sobre quem somos nas rápidas situações cotidianas de nossa vida ganham uma maior consistência à medida que inseridas numa narrativa de nós mesmos que inclua descrições de situações antigas.

Através do uso de macronarrativas responde-se à demanda social de estabilidade. Assim, a estabilidade do self, nesta perspectiva construcionista, deixa de ser decorrente da organização interna do self e passa a ser entendida como uma construção narrativa, decorrente do uso de determinadas formas de interligar os eventos. De um ponto de vista construcionista, não há demanda inerente para a estabilidade de uma identidade. As narrativas de estabilidade servem à descrição de uma identidade duradoura, integral e coerente, gerando segurança naqueles relacionamentos que requerem tal descrição para sua manutenção.

São nos contextos de relacionamento que as narrativas têm suas potencialidades e limites determinados, pois a possibilidade de se descrever através de uma narrativa de qualquer tipo depende da comunidade na qual se está inserido, dos relacionamentos aí existentes. Além da avaliação moral a que estão sujeitas quaisquer narrativas de self, estas na maior parte das vezes incluem ações de outros participantes. Assim, a validade narrativa depende da confirmação do outro, de seu acordo quanto à forma como foi descrito. Constrói-se, assim, uma rede de identidades recíprocas. Para Gergen (1997), "As identidades, neste sentido, nunca são individuais; cada uma é suspensa em um conjunto de relacionamentos precariamente situados. As reverberações sobre o que acontece aqui e agora - entre nós - podem ser infinitas" (p. 209). Esta forma de descrever o self como uma narrativa contada por nós e pelos outros sobre nós, a partir de determinados vocabulários e discursos socialmente disponíveis, reafirma as perspectivas construcionistas propostas por Gergen a respeito da especificidade sóciohistórica das descrições do mundo, da valorização dos relacionamentos na sustentação do conhecimento e da interligação entre conhecimento e ação, abrindo espaços para reflexões críticas sobre as contribuições da Psicologia para a manutenção e/ou transformação da cultura.

\section{A Dualidade da Ciência Psicológica: Pessoa, Práticas Discursivas e Selves}

A discussão sobre ciência e sobre as noções básicas que orientam uma perspectiva construcionista social é desenvolvida por Harré (1998) em seu livro The singular self, a partir da proposição de uma Psicologia Discursiva para a investigação dos fenômenos psicológicos. De acordo com este autor, a Psicologia Discursiva desenvolveu-se como uma forma particular de explicação, onde o discurso, como uma produção essencialmente humana, histórica e culturalmente situada, orientada por regras e convenções sociais normativas, assume lugar de destaque.

A transição para uma Psicologia Discursiva, segundo ele, marca algumas mudanças em relação aos paradigmas tradicionais que orientavam a ciência psicológica até então. A Psicologia passa a focalizar os processos de significação e de construção conjunta de sentidos entre observadores e sujeitos, não havendo uma preocupação em garantir a veracidade ou unicidade de uma determinada descrição. Os discursos são considerados como produzidos conjuntamente pelas pessoas dentro de grupos particulares, sendo regidos por determinadas regras e convenções sociais, que orientam esta possibilidade sempre local e contextualizada de construção (Harré \& Gillet, 1994). 
Do mesmo modo, para a Psicologia Discursiva, os fenômenos psicológicos deixam de ser descritos como expressões de um mundo mental interior, e passam a ser vistos como descrições socialmente contextualizadas, que engendram determinadas práticas sociais e formas de relacionamento. Por este ponto de vista, a especificidade do ser humano reside na sua capacidade para a linguagem e, assim, o foco de investigação na Psicologia recai sobre os diferentes discursos através dos quais os fenômenos psicológicos são produzidos pelas pessoas em seus relacionamentos. Conforme descrito por Harré (1998), “a pessoa não tem atributos psicológicos outros além de seu poder de produzir o fenômeno psicológico no fluxo das ações públicas e privadas" (p.15).

A partir disto, Harré (1998) afirma o caráter essencialmente dual da ciência psicológica e sua dupla ontologia. Segundo ele, antes de tudo, ser uma pessoa implica em ter uma dotação biológica característica, que possibilita a aquisição da linguagem e o ingresso no universo discursivo. Cérebros, sistema nervosos e aparelhos perceptivos constituem as pessoas de uma determinada forma e funcionam como "ferramentas" necessárias para o desenvolvimento da linguagem e para a realização das mais diversas atividades. Para Harré, "todo fenômeno psicológico só é possível em virtude de uma certa condição ou estado do cérebro e sistemas nervosos daqueles engajados na atividade" (p.15), o que denomina de "condição capacitante". Algumas destas condições são parte da própria natureza humana, enquanto outras podem até mesmo ser estabelecidas por treino ou prática.

No desenvolvimento desta primeira ontologia, Harré (1998) baseia-se fundamentalmente nas concepções de Vygotsky acerca do desenvolvimento humano e, em especial, dos processos de aquisição da linguagem. Para Harré, a dotação biológica humana (cérebro, sistema nervoso) se manifesta inicialmente em atividades mentais desordenadas e indiferenciadas, que são posteriormente organizadas através da aquisição de habilidades discursivas, que se constituem como característica central na organização da experiência humana. É esta transição para a possibilidade de linguagem que diferencia a espécie humana de qualquer outro ser vivo e marca sua dimensão etológica essencial: “apenas os seres humanos, até onde sabemos, são capazes deste trato cognitivo de construir sentidos, de criar ferramentas discursivas. Tudo o que é característica da vida humana reside sobre o exercício desta capacidade" (p.16).

Embora considerada como parte da ciência psicológica, esta dotação biológica é característica da neurofisiologia de nossos corpos, e não se constitui propriamente como o campo preferencial de investigação de uma Psicologia Discursiva. Para Harré (1998), a Psicologia Discursiva desenvolve-se especificamente a partir de uma segunda ontologia, que busca compreender o modo como os diversos fenômenos psicológicos são produzidos discursivamente. Ou seja, dada a possibilidade humana de aquisição da linguagem, a Psicologia Discursiva elege como objeto de sua investigação as construções lingüísticas e gramaticais, os discursos e narrativas de vários tipos através dos quais as pessoas constroem conjuntamente realidades pessoais e sociais.

De acordo com Harré (1998), temos a "habilidade de relatar como as coisas são a partir de nosso ponto de vista pessoal, de assumir ou repudiar responsabilidade por nosso ponto de ação e de contar nossas estórias como envolvendo linhas de vida" (p.14). Cada uma destas habilidades é discursiva e a investigação destas narrativas como construções relacionais parte de um contexto social mais amplo, caracteriza a especificidade de uma Psicologia Discursiva. Para esta segunda ontologia, a análise da linguagem é proposta como técnica preferencial de investigação, onde o estudo empírico da gramática é visto como o lugar onde formas relevantes da experiência humana podem melhor ser reveladas; e o uso do Eu (pronome gramatical de primeira pessoa) revela os diferentes modos de expressão de nosso senso de self. Assim, ao mesmo tempo em que Harré assume a dualidade da ciência psicológica, ele elege uma ontologia como preferencial, definindo como campo de estudo da Psicologia Discursiva não a investigação dos processos biológicos, mas a investigação das práticas discursivas nas quais os fenômenos psicológicos são ativa e relacionalmente construídos. Para este autor, esta visão da Psicologia Discursiva como uma ciência dual é coerente com a abordagem construcionista social, que é descrita por ele a partir de duas noções centrais nas quais tanto a universalidade como a diversidade do que é ser uma pessoa são contempladas. Em primeiro lugar, o construcionismo social enfatiza a centralidade do relacionamento inicial com outros seres humanos para a aquisição de características psicológicas, habilidades e tendências tipicamente humanas - assumindo o conceito de interação 'simbiótica' proposto por Vygostsky. Para ele, a natureza relacional do ser humano é uma condição etológica essencial, e isto impõe uma dimensão de universalidade sobre o que é ser uma pessoa. Ao mesmo tempo, esta interação humana é parte de um contexto cultural específico, que dá margens à diversidade no que cada ser humano pode de fato se tornar.

O construcionismo social também enfatiza a base lingüística das práticas humanas. Aqui, novamente se impõe a dimensão de universalidade sobre o que cada ser humano pode produzir em termos de significado, uma vez que, invariavelmente, existirão condições morais e materiais que orientam o uso da linguagem. Ao mesmo tempo, a natureza essencialmente cultural da semântica e da sintaxe lingüística marca a natureza diversa da linguagem e das possibilidades humanas de significação. 
Além disso, Harré (1998) considera a existência de algumas condições que estão fora de qualquer discurso, tais como as próprias condições que tornam a linguagem possível - como expressões naturais de sentimento, de ponto de vista perceptual, etc, sem as quais não existiria sequer a possibilidade de desenvolvimento de um sistema simbólico; uma fundação etológica essencial - incluindo tanto o aspecto relacional como a possibilidade lingüística; e a existência de uma ordem moral em curso, sem a qual não haveria qualquer possibilidade de discurso e significação. Harré (1998) argumenta, contudo, que esta ênfase dada às condições capacitantes para o uso da linguagem não desconsidera as dimensões relacional, temporal e contextual do processo de produção do self. Para ele, as pessoas constróem seus atributos pessoais, habilidades e capacidades, bem como sentidos sobre o mundo material a sua volta, nas práticas discursivas, na interação com outras pessoas, e esta construção estará sempre sujeita a variações em função de aspectos culturais e temporais em curso. Esta visão de Psicologia Discursiva favorece, entre outras coisas, uma compreensão acerca do modo como se dá a construção da pessoalidade no discurso, isto é, de como adquirimos nosso senso de unicidade, singularidade e continuidade pessoal as noções centrais que sustentam a concepção acerca do que é ser uma pessoa em qualquer cultura, segundo Harré.

Conforme afirmamos anteriormente, segundo Harré (1998), a Psicologia Discursiva propõe que a especificidade do ser humano reside em sua capacidade de produzir sentido sobre si mesmo e sobre o mundo em que vive, isto é, em sua habilidade de produzir explicações discursivas. Para ele:

A tese psicolingüística da construção social da pessoalidade é simplesmente a de que, ao adquirir a capacidade gramatical do uso dos artifícios de primeira pessoa, as singularidades do self são trazidas para a coordenação como o senso que eu tenho de meu próprio ser como uma singularidade, meu contínuo ponto de vista. (p.18)

Na defesa desta concepção, o autor começa desconstruindo o conceito de self, usualmente referido como entidade na ciência psicológica, pressupondo algum tipo de mentalismo e de interioridade. Para ele, o self não passa de um "artifício retórico", uma forma de descrição através da qual construímos gramaticalmente nosso "senso de self", de modo a afirmar nossa unicidade, singularidade e continuidade como pessoa.

Assim, ter um senso de selfé ter um senso de localização como pessoa, um senso de ter um ponto de vista único a partir do qual se fala e age, e de ter um curso de vida relativamente contínuo e singular. Este aspecto, denominado por Harré de "self1", encontra-se intimamente ligado a noção de corporeidade e da impossibilidade de existir qualquer outro ser humano com a mesma trajetória espaço-temporal.
De acordo com as idéias do construcionismo social por ele propostas, este aspecto remete à dimensão de universalidade do que é ser uma pessoa, algo próprio do ser humano.

Além disso, ter um senso de selfé ter também um senso de singularidade, de se ter um conjunto único de atributos pessoais que, mesmo mutáveis, constituem uma pessoa como única e diferente de todas as demais. Ainda que haja a possibilidade de semelhança com outros, ser uma pessoa implica em ser diferente dos outros em todas as suas propriedades, ainda que possa haver inúmeras semelhanças. Este aspecto é denominado por Harré de "self 2", e guarda relação com um terceiro aspecto, o "self 3 ", que se refere às impressões que esta totalidade de atributos pessoais provocam no outro.

A partir disso, Harré (1998) propõe que o selfnão constitui uma entidade, mas sim "uma posição a partir da qual a pessoa percebe o mundo e o lugar a partir do qual age" (p. 3). Aqui, a diversidade do que é ser uma pessoa é enfatizada, também em concordância com a perspectiva construcionista social por ele descrita. Assim, enquanto os selves são descritos como ficções gramaticais, as pessoas são descritas como seres reais, existentes, constituídas pelo conjunto de nossos sensos de self - o que é descrito e sintetizado no seguinte "modelo padrão":

Pessoa $\{$ Self 1, Self2, Self 3$\}$.

Cada um destes selves encontra sua forma particular de expressão nos discursos e formas narrativas diversas, de modo que as práticas discursivas se constituem como lugar privilegiado para a investigação da pessoalidade e das formas de vida humana. Para ele, enquanto a expressão do self 1 pode ser observada em nossa gramática pronominal, especialmente através do uso do pronome de primeira pessoa, pelo qual assumimos nosso ponto de vista pessoal e nossa localização como ser responsável, a expressão de nosso self 2 pode ser verificada nos diversos discursos autobiográficos, nos quais organizamos discursivamente nossos atributos pessoais em uma história de vida descrita como relativamente contínua e singular.

$\mathrm{Na}$ compreensão do modo como se dá esta produção discursiva do self, a Teoria do Posicionamento (Harré \& Van Langenhove, 1999) exerce um papel central. A partir dela, se concebe que as pessoas estão ativamente se posicionando nas práticas discursivas de que participam e assim construindo conjuntamente seu senso de self. Aqui, a diversidade do que é ser uma pessoa pode ser melhor evidenciada, uma vez que as pessoas podem ocupar diversas posições, de acordo com os jogos de posicionamento em curso, que irão variar em função do contexto, do tipo de relacionamento e das pessoas envolvidas.

Em síntese, podemos afirmar que a proposta construcionista social discutida por Harré e sistematizada a partir da descrição das particularidades de uma Psicologia Discursiva, deriva em uma explicação ontológica dupla 
acerca do que é ser uma pessoa. Para este autor, ser uma pessoa remete a pensar um ser com uma corporeidade única, mas com atributos e poderes diversos e uma história distinta de todos os outros seres, que deve assumir-se como ator responsável, com direitos e deveres em relação a outras pessoas. São estas as características básicas que definem o que é ser uma pessoa e que demandam por um discurso de self referido à unicidade, singularidade e continuidade da experiência pessoal. A proposta de Harré (1998) é a de que "o conjunto de conceitos pessoais que caracterizam os discursos de selfassume o papel de uma gramática, de regras que tornam o discurso sobre pessoas possível" (p.72).

Ter um senso de selfé estar determinado a se expressar de determinadas formas, seguindo as convenções normativas que orientam e legitimam nossas descrições acerca de nós mesmos. Portanto, a análise da gramática e das formas narrativas é o campo de investigação preferencial de uma ciência psicológica discursivamente orientada, uma vez que é nos discursos que a maioria dos fenômenos psicológicos são construídos, bem como nosso senso de self.

\section{Construcionismos em Diálogo: Semelhanças, Diferenças e Implicações para o Conceito de Self}

Considerando nosso objetivo de colocar em diálogo as diferentes descrições de Gergen e Harré acerca do construcionismo social, visão de ciência e self, propomos uma tabela comparativa (ver Tabela 1) onde as principais considerações destes autores sobre estes três aspectos encontram-se sintetizadas. Privilegiamos até este momento uma análise da lógica interna de cada uma das propostas sendo possível explicitar os argumentos que justificam determinada forma de se conceber e estudar o self.

Tabela 1

Comparação das Descrições de Construcionismo e suas Implicações segundo Gergen e Harré

\begin{tabular}{|c|c|c|}
\hline Definiçôes & Gergen & Harré \\
\hline $\begin{array}{l}\text { Construcionismo } \\
\text { Social }\end{array}$ & $\begin{array}{l}\text { 1) a especificidade cultural e histórica de } \\
\text { conhecermos o mundo. } \\
\text { 2) a primazia dos relacionamentos humanos na } \\
\text { produção e sustentação do conhecimento. } \\
\text { 3) a interligação entre conhecimento e ação. } \\
\text { 4) a valorização de uma postura crítica e } \\
\text { reflexiva }\end{array}$ & $\begin{array}{l}\text { 1) condição etológica essencial: universalidade do } \\
\text { relacionamento inicial / diversidade pelas } \\
\text { especificidades do contexto cultural. } \\
\text { 2) base lingüística essencial: universalidade das } \\
\text { condições morais e materiais para a possibilidade } \\
\text { de linguagem / diversidade cultural da semântica } \\
\text { e da sintaxe da lingüística. }\end{array}$ \\
\hline Ciência & $\begin{array}{l}\text { 1) Psicologia: desafio à suposição de um } \\
\text { objeto e metodologia únicos. } \\
\text { 2) Empreendimento da cultura } \\
\text { - Epistemologia social } \\
\text { - Ciência como prática social } \\
\text { 3) Visa gerar inteligibilidades } \\
\text { - Crítica interna, cultural e pesquisa de } \\
\text { desalojamento } \\
\text { - Desconstrução, democratização e } \\
\text { reconstrução }\end{array}$ & $\begin{array}{l}\text { 1) Psicologia: estudo da pessoa } \\
\text { 2) Epistemologia dualista: } \\
\text { - aspectos biológicos como condição capacitante } \\
\text { - produção discursiva dos fenômenos psicológicos } \\
\text { 3) Psicologia discursiva: } \\
\text { - objeto: pessoa \{self1, self } 2 \text {, self } 3\} \\
\text { - método: estudo empírico da gramática e } \\
\quad \text { das formas narrativas }\end{array}$ \\
\hline Self & $\begin{array}{l}\text { 1) Self como discurso } \\
\text { 2) Discursos sobre o self } \\
\text { a) Romântico } \\
\text { b) Moderno } \\
\text { c) Pós-moderno: self saturado } \\
\text { - vertigem do dever } \\
\text { - expansão da auto-dúvida } \\
\text { - racionalidade em recessão } \\
\text { 3) Narração social do self } \\
\text { - Estrutura narrativa } \\
\text { - Pragmática da narração } \\
\text { - Redes de identidades recíprocas: } \\
\text { self relacional }\end{array}$ & $\begin{array}{l}\text { 1) Pessoa como existente/ } \\
\text { selves como artifícios retóricos } \\
\text { - modelo padrão: pessoa }\{\text { self } 1 \text {, self } 2 \text {, self } 3\} \\
\text { 2) Condições etológicas: demanda pelo discurso } \\
\text { da unicidade, singularidade e continuidade - self } \\
\text { singular } \\
\text { 3) Pessoa em relação: nas práticas discursivas a } \\
\text { pessoa se constitui ao assumir determinadas } \\
\text { posições } \\
\text { 4) Formas de expressão da personalidade no } \\
\text { discurso: } \\
\text { - Gramática pronominal - self } 1 \\
\text { - Narrativas autobiográficas - self } 2 \\
\text { - Impressões de outrem sobre o self - self } 3\end{array}$ \\
\hline
\end{tabular}


Conforme apontamos na Tabela 1, Harré e Gergen partem de diferentes posições epistemológicas para o entendimento da produção do conhecimento. Enquanto Gergen parte de uma desconstrução da noção de realidade, enfatizando a natureza construída de nossas descrições de mundo e o caráter situado das mesmas - assim afirmando a multiplicidade possível de descrições ontológicas - Harré parte da dualidade ontológica sustentada tanto pela universalidade da condição relacional e lingüística do ser humano quanto pela diversidade possível de significação, considerando o uso situado da linguagem e a influência do contexto histórico e cultural.

Deste modo, a realidade da condição etológica humana - de um ser em relação e com capacidade para linguagem é adotada por Harré, o que caracteriza uma forte distinção em relação à visão de Gergen. Nem mesmo este tipo de realismo é endossado por Gergen, que entende ser este também mais um discurso possível acerca da realidade do mundo e da natureza humana, um discurso situado, socialmente construído e, portanto, não universal. Contudo, no que tange à diversidade das formas de significação e a influência das condições culturais e relacionais nos processos de produção de sentidos, as propostas destes autores se aproximam. Ambos apontam para a importância do contexto sócio-cultural e da dimensão temporal nos processos relacionais de significação.

A importância do relacionamento com o outro no construcionismo de Harré é decorrente de uma dotação biológica ao nascer, de sua fragilidade, de uma condição etológica específica: a dependência do outro para seu desenvolvimento. Nesta construção teórica, a relação com o outro se refere a uma inevitabilidade ontológica. Já em Gergen não se trata mais de uma inevitabilidade ontológica, mas de uma opção epistemológica do autor. A partir de uma epistemologia social, a relação com o outro é considerada a unidade básica para o estudo da construção social da pessoa, e como tal, o relacionamento precede a pessoa. Como podemos ver, são diferentes justificativas para a ênfase comum nos processos sociais de construção da realidade. Esta diferença é mais um reflexo da tensão entre teses realistas e anti-realistas no campo das idéias construcionistas.

A proposta de Gergen, fundamentada nas teses antirealista e anti-essencialista, bem como na primazia dos relacionamentos humanos para a sustentação do conhecimento e das descrições de mundo, gera uma visão também particular acerca da ciência e suas formas de investigação. Para Gergen, a Psicologia é vista como um empreendimento cultural, produzindo descrições específicas, possíveis em função das contingências dos relacionamentos em determinada comunidade e do contexto em que são construídas. Assim, nesta perspectiva, a ciência é vista como prática social, sustentada por uma epistemologia social. De acordo com estes princípios, a Psicologia não deve supor um objeto único e uma metodologia particular de investigação.

Por outro lado, a visão construcionista social de Harré, considerando os aspectos universais do humano como condições capacitantes para a aquisição da habilidade discursiva, leva à proposição de uma epistemologia dualista, pautada em uma dupla ontologia. Para ele, a Psicologia deve considerar tanto os aspectos biológicos próprios da etologia humana, quanto as práticas discursivas onde os fenômenos psicológicos são produzidos - sendo estas o objeto de estudo preferencial de uma Psicologia Discursiva. Assim, ao contrário de Gergen, Harré propõe a "pessoa" como objeto de investigação, focalizando, em especial, o modo como os "selves", sendo artifícios retóricos, são utilizados na construção de nosso senso de pessoalidade e, em conseqüência, elege também o estudo da gramática como a metodologia preferencial de uma Psicologia Discursiva.

Por fim, estas diferentes premissas construcionistas e concepções acerca dos empreendimentos da ciência psicológica geram também reflexões e entendimentos distintos acerca do self. Embora ambos os autores concebam o self como uma construção discursiva e situada, produto dos relacionamentos entre as pessoas, esta conclusão deriva de construções teóricas distintas e resultam em propostas específicas de investigação e prática no campo da psicologia.

Ao situar o self como construção social, Gergen chama a atenção para os diferentes discursos construídos sobre o self(discurso romântico, moderno e pós-moderno) e para as condições históricas que propiciaram e sustentaram suas construções. Assim, aponta para o caráter contextual e histórico destas descrições, desconstruindo a noção de que existe uma demanda imanente pela estabilidade de uma identidade e dando visibilidade aos processos contemporâneos de saturação social, que parecem propiciar a emergência de um novo vocabulário de self, onde a diversidade e multiplicidade narrativa são promovidas. A partir disso, Gergen aponta para a necessidade de refletirmos acerca das implicações destes diferentes discursos de self, verificando o uso que fazemos deles em nossas práticas sociais.

Dando destaque aos processos de produção lingüística e relacional do self, Gergen focaliza o estudo das narrativas de self - tanto no que se refere à estrutura narrativa quanto à função pragmática da narração. Por fim, Gergen propõe um self relacional, produto de discursos sociais compartilhados que se presentificam no relacionamento atual entre os interlocutores, na construção de redes de identidades recíprocas.

Também Harré situa o self como discurso, mas a partir de um ponto de vista bastante distinto. Partindo do modelo padrão "Pessoa \{self1, self 2 e self 3$\} "$ ", ele entende os selves 
como artifícios retóricos pelos quais expressamos as noções de unicidade, singularidade e continuidade. Para ele, estas são descrições que definem o que é ser uma pessoa em qualquer cultura. Isto porque a corporeidade humana demanda por estas formas discursivas específicas, isto é, pelo discurso do self singular. Em outras palavras, existe uma demanda imanente e natural pelo discurso da unicidade, da singularidade e da continuidade pessoal e, estes aspectos encontram na gramática suas formas particulares de expressão. O self 1 pode ser observado através do uso dos pronomes gramaticais de primeira pessoa, o self 2 pode ser evidenciado nos discursos auto-biográficos e o self 3 nas referências de uma pessoa sobre o self de outra.

Assim, a tese dualista de Harré se presentifica também em sua conceituação do self, onde tanto a universalidade como a diversidade são fundamentais. Ao mesmo tempo em que existe uma demanda por um discurso singular do self, Harré ressalta que esta construção vai variar de acordo com o contexto cultural e as convenções narrativas diversas que orientam a construção destes discursos. Além disso, ressalta que esta construção discursiva do self se dá relacionalmente, através dos jogos de posicionamento entre as pessoas. Estas se constituem ao assumirem para si mesmas e atribuírem aos outros determinadas posições, de acordo com as contingências do relacionamento imediato, do contexto cultural e da linha de história em curso.

\section{Considerações Finais}

Ao compararmos estes autores muitas perguntas podem ser levantadas. Contudo, tal como já assinalamos, não objetivamos marcar rigidamente a distinção entre ambos, na afirmação da verdade sobre cada uma destas propostas. Isto seria apenas um artifício retórico. Assim, esperamos ter apontado algumas tensões que atravessam as descrições destes autores construcionistas comuns a vários de seus pares e que se encontram presentes também na relação destes com outras teorias sobre o conhecimento psicológico.

A percepção de que a diferença de entendimento destes autores acerca da natureza do self é coerente com as descrições que fazem do construcionismo bem como de suas visões de ciência, pode favorecer uma escolha metodológica e teórica mais reflexiva para aqueles interessados no estudo do self e da produção discursiva dos fenômenos psicológicos e sociais.

\section{Referências}

Burr, V. (1995). An introduction to social constructionism. London: Routledge.

Danzinger, K. (1997). The varieties of social construction. Theory and Psychology, 7 , $399-416$.

Gergen, K. J. (1985). The social constructionist movement in modern psychology. American Psychologist, 40, 266-275.

Gergen, K. J. (1991). The saturated self. New York: Basic Books.

Gergen, K. J. (1997). Realities and relationships. Cambridge: Harvard University Press.

Gergen, K. J. (1999). An invitation to social construction. London: Sage.

Hacking, I. (1999). The social construction of what? Cambridge: Harvard University Press.

Harré, R (1998). The singular self: An introduction to the psychology of personhood. London: Sage.

Harré, R. \& Gillet, G. (1994). The discursive mind. London: Sage.

Harré, R. \& Van Langenhove, L. (Orgs.) (1999). Positioning theory: Moral contexts of intentional actions. Oxford: Blackwell.

Nightingale, D. J. \& Cromby, J. (1999). Social constructionist psychology. Buckingham: Open University Press.

Parker. I. (1998). Social constructionism, discourse and realism. London: Sage.

Rasera, E. F. (2002). Relatório de pesquisa/ FAPESP. Ribeirão Preto: mimeo.

Shotter, J. (1993). Conversational realities. London: Sage.

Spink, M. J. (1999). Práticas discursivas e producão de sentido no cotidiano. São Paulo: Cortez.

Zuriff, G. (1998). Against metaphysical social constructionism in psychology. Behavior and Philosophy, 26, 5-28.

Sobre os autores

Emerson F. Rasera é Professor Doutor da Universidade Federal de Uberlândia

Carla Guanaes é Professora Doutora das Faculdades COC Ribeirão Preto. É psicóloga do

Núcleo de Apoio Institucional (NAI) do Centro Universitário Barão de Mauá, Ribeirão Preto.

Marisa Japur é Professora Doutora da Universidade de São Paulo, Ribeirão Preto. 


\section{MESTRADO E DOUTORADO EM PSICOLOGIA DO DESENVOLVIMENTO}

2004

Se você é graduado em Psicologia, tem um bom domínio da língua inglesa e deseja se preparar para ser um pesquisador, professor universitário, ou mesmo um profissional de alta qualificação, o Programa de Pós-Graduação em Psicologia do Desenvolvimento da Universidade Federal do Rio Grande do Sul é o local que você procura. Desfrute de um ambiente acadêmico estimulante, onde alunos e professores convivem diariamente, com dedicação integral ao estudo e à pesquisa. Escreva-nos pedindo maiores informações.

INFORMAÇÕES E INSCRIÇÃO

UFRGS

UNIVERSIDADE FEDERAL

DO RIO GRANDE DO SUL

\section{Instituto de Psicologia}

PROGRAMA DE PÓS-GRADUACCÃO EM PSICOLOGIA DO DESENVOLVIMENTO

Secretaria do PPG em Psicologia do Desenvolvimento - UFRGS

Rua Ramiro Barcelos, 2600, térreo Campus da Saúde

90035003 Porto Alegre RS Brasil

Fone: (51) 33165246 Fax: (51) 33165473

http://www.psicologia.ufrgs.br

E-mail: ppgdesen@ufrgs.br 